\title{
POLITICAL ELITE BEHAVIOR EFFECTIVENESS IN COMBATING THE COVID-19 PANDEMIC: A CASE STUDY OF VIETNAM
}

\author{
Huong Thi Tran \\ Academy of Journalism and Communication (AJC), HCMA, Vietnam
}

\begin{abstract}
The article aims to develop an empirical approach to identifying the key factors in the political elite behavior effectiveness in combating the COVID-19 pandemic propagation exemplified by Vietnam. Using regression analysis and the Chow test, we identified the key behavioral factors that affect the effectiveness of the fight against the COVID-19 pandemic in terms of mortality rates and the state of the economy. The study sample was formed by data from 67 countries worldwide for 2020 . The results suggest that the Rule of Law significantly influences the state of the economy in a pandemic. Their impact on economic efficiency does not depend on the world leaders' gender. The COVID-19 mortality rate is also significantly affected by the Global Health Security Index, gender, and cultural factors. Based on the constructed linear multivariate regression models, we calculated the contribution of significant factors to the effectiveness of combating the pandemic in Vietnam, their stimulating and de-stimulating effects compared to the average values of these indicators for the sample countries.
\end{abstract}

Keywords: Vietnam, political leaders, behavior, political regime, COVID-19, community, humanitarian crisis

DOI: http://dx.doi.org/10.15549/jeecar.v8i2.674

\section{INTRODUCTION}

In the current context of the COVID19 pandemic propagation, people's daily routine is changing every day, due to the disequilibrium in the hierarchy of values between health, economic well-being, security and freedom of movement (Herrera et al., 2021). This, in turn, increases the importance of public trust in government institutions as one of the key factors in the success of public policies to combat the pandemic, whose intensity of spread is largely determined by the behavioral response of the community (Herrera et al., 2021). In the current conditions, political leaders are characterized by different levels of trust popularization in countries around the world. According to the results of the Edelman Trust Barometer 2021, the countries of Asia, particularly China and India, have the highest level of trust in the government among the countries under study (Edelman Trust Barometer 2021, 2021). In the midst of a global outbreak of the COVID-19 pandemic, political leaders in Western countries may lose credibility due to ineffective pandemic control policies. However, the Vietnamese political leaders have come up with suitable policies, well-controlled 
the COVID-19 epidemic across the country and received the trust and support of the people.

To date (as of January 20, 2021), Vietnam has coped with the pandemic having only 1,544 COVID-19 cases and 35 fatalities (Hasell et al., 2020). Vietnam's success in controlling the COVID-19 pandemic is thanks to the wise leadership of the Communist Party as well as close management of The Government of the Socialist Republic of Vietnam. In view of certain changes in the structure of social benefits during a pandemic, a reduced level of infection and a decrease in the viral infection spread come to the fore, which can be achieved through social distancing (Qureshi et al., 2021). In a pandemic, the people's behavior in society is universally determined by the perception of risks, which certainly deeply affects the political sphere and disrupts the established institutional format; in turn this behavior discredits political practices that are familiar and deeply rooted in the current community.

Many scholars note that the cultural and religious factor should underpin political elite behavior effectiveness in combating a pandemic in such countries as Iran, and consideration of this factor will ensure a higher level of government legitimacy and compliance with the public safety requirements.

However, on the other hand, countries with where power belongs to the people cannot apply authoritarian methods of social pressure. According to numerous studies, the effectiveness of the political leaders' behavior in ensuring state social control depends more on voluntary compliance than on state coercion (Sjöstedt \& Linell, 2021; Van Bavel et al., 2020; Rangone, 2018). Trust is the foundation upon which the legitimacy of public institutions is built and is crucial to maintaining social cohesion (Rangone, 2018). The general public has successfully exploited this gap in social control (Rangone, 2018). Although, as practice shows, during a pandemic in many countries, the government legitimacy remains without authoritarianism at a very high level, the community trusts the political elite and the healthcare system, for example, in South Korea, Taiwan, Germany (Yang \& Tsai, 2020) and others. But in various countries worldwide, political leaders are forced to apply unpopular decisions. The introduction of strict quarantine measures, restricting the free travel of people and implementing strict social distancing measures, closing borders and disbanding trade chains for an indefinite period discredit the political elite legitimacy. Public demand for free travel, growth of economic prosperity and crisis manifestations of economic development equally continue reducing the legitimacy of state institutions (Megits, 2016; Archer \& Levey, 2021). Therefore, there is an increase in the polarization of policy regime of freedom and equality between all people, for example, in the United States, where this trust in government is lacking and the fight against coronavirus faces big challenges (Archer \& Levey, 2021). Italy can also serve as an example. This country with a policy regime of freedom and equality between all people had the highest fatality and virus spread rate in 2020 (Archer \& Levey, 2021). But at the same time, it had the level of state institutions' legitimacy comparable to that of Hong Kong (Edelman Trust Barometer 2020, 2021). Also, it belonged to the countries with the highest life expectancy in the world (Hasell et al., 2020).

Consequently, the high level of political leaders' legitimacy makes it possible to form a factor of safety for general consistency in society in taking unpopular decisions, saving the time and money that will allow maintaining general order to achieve long-term goals. Since precisely political leaders are the main institution for making decisions and ensuring the solidarity of public opinion, the political leaders' behavior effectiveness aimed at forming the proper meaning and public perception of what is happening becomes acutely relevant. Many scholars use the example of Germany to conclude that, in addition to the country's national wealth (Desson et al., 2020), a decent level of funding for the health care system (Desson et al., 2020), parliamentary policy regime of freedom and equality between all people (Yang \& Tsai, 2020) and the political elite consensus culture (Yang \& Tsai, 2020), the individual qualities of a political leader: decisiveness, calmness and temperament play a significant role in the successful fight against the pandemic (Windsor et al., 2020; Johnson \& Williams, 2020). In addition, there is a viewpoint that women political leaders are characterized by more flexible and effective behavior in the 
process of implementing anti-crisis policies in the context of combating the spread of the COVID-19 pandemic, as they are more sympathetic and sensitive to public problems. Women politicians, heading such countries as New Zealand, Taiwan, Finland, earned high praise for their actions during the pandemic because they were able to form a high-level base for social capital in their countries, subordinating personal goals to collective actions.

When assessing the political leaders' behavior effectiveness during the COVID-19 pandemic, scholars (Windsor et al., 2020; Coscieme, Fioramonti \& Trebeck, 2021; Erman \& Medeiros, 2021) focus on morbidity and mortality rates, the minimization of which is a sign of effectiveness. However, this approach to assessing effectiveness is incomplete since it does not account for the "trade-off" between health and the economy (Herrera et al., 2021), which implies that social distancing and isolation make the most effective method for combatting a pandemic; these measures are achieved by limiting the service sector functioning, switching to telecommuting, which negatively affects the economy. Saving human lives is an unambiguous priority and a benchmark in the fight against the pandemic, but declining economic performance also threatens human lives through lower incomes, increased poverty and hunger (Nurunnabi, 2020; Nurunnabi, Alhawal \& Al Bassam, 2020). According to the World Health Organization, in 2019, about 690 million people were suffering from hunger in the world; and according to preliminary estimates, at the end of 2020, this figure grew to 820 million people (World Health Organization, 2021). As experts assess, 12 thousand people could die per day by the end of the year as a result of hunger linked to COVID-19, which may be higher than the COVID19 fatality rate (Vogelstein \& Bro, 2020; Grech \& Grech, 2020).

Consequently, the COVID-19 pandemic has confirmed the strength and exacerbated the weakness of various political elite behaviors and the functioning of political systems. Therefore, within the framework of this research, an approach has been proposed to assess the political leaders' behavior effectiveness regarding the indicators of morbidity and economic development of the countries they head by substantiating the following hypotheses of scientific knowledge:

H1: The global leaders' gender influences the behavior in effectiveness while combatting the COVID-19 pandemic. This Hypothesis is based on studies (Windsor et al., 2020; Johnson \& Williams, 2020; Garikipati \& Kambhampati, 2021), which indicate that women leaders are more effective in countering the spread of COVID-19 from the position of minimizing the number of infected and mortality rates.

H2: The rule of law, policy regime of freedom and equality between all people and state of the health system have the most significant impact on the effectiveness of the fight against the COVID-19 pandemic. This Hypothesis is based on a study (Vasiljeva et al., 2020), which indicates the importance of discipline factors (expressed through the Rule of Law Index and the People power Index (DI)) and the state of the health care system in resisting the increase in the number of cases among the countries of Eastern Europe.

H3: the cultural peculiarities of the country have a more significant impact on the effectiveness of countering the pandemic compared to the leader's gender. Among the features that affect the effectiveness of the fight against a pandemic, Windsor et al. (2020), Erman and Medeiros (2021) listed the following: power distance, uncertainty avoidance, individualism, masculinity, long-term orientation, indulgence, which corresponds to the model of cultural typology, according to Hofstede (Hofstede Insights, 2021).

H4: economic development indicators, with the main one being GDP per capita, have a twoway causal relationship with the COVID-19 prevalence rates. On the one hand, per-capita GDP depends on the scale of the pandemic as a result of the response to measures of social distancing, isolation, restrictions on the service sector activities and, on the other hand, it should influence the effectiveness of the fight against the pandemic, determining the potential funding opportunities for measures aimed at combating the virus. But as evidenced by the results of a study (Windsor et al., 2020), instead of a positive influence on the effectiveness of the fight against the virus, a pattern was revealed that more developed countries were more affected by the pandemic than less developed ones. 
H5: the people power characteristics of the population determine the effectiveness of the fight against a pandemic: average age, average life expectancy, and health status (Abate, Checkol \& Mantefardo, 2021; Polidori et al., 2021).

\section{MATERIALS AND METHODS}

\section{Indicators of Assessing the Political} Leaders' Behavior Effectiveness during the COVID-19 Pandemic

We used mortality rate (the number of deaths due to a disease divided by the total population) as an indicator of the effectiveness of combating the pandemic to ensure health rather than the number of deaths (Bosancianu et al., 2021; Maiti et al., 2021). Also, the indicator of incidence was not used (Maiti et al., 2021), because of the different levels of testing for COVID-19 among the countries worldwide (Hasell et al., 2020). In countries such as Luxembourg $(2,638,542$ tests per 1,000 population), the United Arab Emirates $(2,112,184$ tests per 1,000 population), Denmark (1,813,648 tests per 1,000 population), testing is more widespread (Hasell et al., 2020), and thus, there is a greater likelihood to identify infected people. While in countries where the percentage of the population coverage is much lower, for example, Madagascar (3,655 tests per 1,000 population), Malawi (4,409 tests per 1,000 population), Nigeria (4,599 tests per 1,000 population) (Hasell et al., 2020), testing is carried out in critical cases associated with the need for hospitalization (Vasiljeva et al., 2020). Mild cases or asymptomatic cases of the disease in these countries are not recorded, which lowers the statistics when compared to the countries with mass testing. When using the mortality indicator, there is also a risk of distorting the real situation with the virus, but this risk is much lower than in the case of the morbidity rate. In addition, to neutralize this factor, the study adjusted the mortality indicator for testing coverage by dividing by the number of the performed virus tests. The dynamics of the spread of the virus across countries is not identical: the stages of growth and decline in morbidity and mortality do not have the same duration in all countries (Hasell et al., 2020). Therefore, this study did not use mortality indicators for a certain date from the first case of contagion or from the first case of recorded death, for example, on the 30th, 60th, 90th days, as in (Windsor et al., 2020), but the mortality rate for 2020 is used. Since there are no estimates as to what rates of GDP decline are critical and how they influence the mortality rate, this study uses 2 particular performance indicators: 1) the GDP per capita growth rate $\left(\mathrm{GDP}_{\mathrm{GR}}\right) ; 2$ ) the COVID-19 mortality rate of the total population, adjusted for testing rate $\left(\mathrm{MOR}_{\text {covid }}\right)$. For all countries of the world (including China, where cases of COVID-19 infection were recorded in 2019), the consequences of the pandemic affected the economy in 2020. Therefore, $\mathrm{GDP}_{\mathrm{GR}}$ is calculated as the GDP per capita growth rate in 2020 compared to 2019.

\section{Research Sample and the Results Processing Methods}

To assess the influence of the gender factor on the effectiveness of combating the pandemic, the regression analysis was applied - linear and nonlinear (using 2nd-4th orders polynomial, logarithmic, and power function) estimation.

The following indicators were used as independent variables for the models:

GEND $_{\text {LEAD }}$ is the gender identity of the country's political leaders (the President, the King, the Prime Minister, the Governor-General, the Chairman of the Councilof Ministers, etc., depending on the form of government). The following values of the variable were used: 0 - if the main leadership position (the President - in a presidential or presidential-parliamentary republic, the Prime Minister, the Chancellor - in a parliamentary or parliamentary-presidential republic) is held by a woman; 1 - if men hold all leadership positions in the country. The countries where both women and men occupy top leadership positions, and the countries where men hold the main leadership position, but with women representation (for example, a woman as the Prime Minister in a presidential or presidential-parliamentary republic, the President in a parliamentary or parliamentarypresidential republic) were relied on for statistical evaluation: calculation of average indicators and t-test for independent samples. When constructing regression models to ensure their adequacy, these countries were excluded from the sample. Since political decisions during a pandemic were operational in nature and 
immediately influenced the effectiveness of the fight, gender was determined without a time lag.

The time period for the study was 2020 . The starting point for determining the indicator values was the date earlier of the two indicated: 1) the date of the start of introducing antiepidemic measures in the country, 2) the date of the 1 st case of infection in the country. The terminal date is December 31, 2020.

GDP is a per-capita GDP indicator expressed in US dollars. This indicator is the economic basis for combating a pandemic and its impact on the effectiveness of fighting a pandemic is possible both with a time lag, and without it. Therefore, the study considered the values of this indicator for $2020-G_{(2020)}$, for $2019-G D P_{(2019)}$, and for 2018 - GDP $(2018)$ (Knoema, 2021a).

LAW is the Rule of Law Index. The potential impact of this indicator on the effectiveness of the fight against the pandemic is reflected through the population's abidance to laws and strict compliance with quarantine restrictions. This indicator value for 2020 was used in the study (World Justice Project, 2021).

DEM is the DI. This indicator, like the previous one, characterizes the degree of compliance with anti-epidemic measures. But unlike the previous one, which affects compliance with the law, this indicator affects the degree of compliance with government recommendations on behavior during the pandemic, which are not legally enshrined. The DEM indicator value for 2020 was used in the study.

HEAL is Global Health Security Index. This indicator specifies the ability of national health systems to counteract the pandemic through the prevention quality sub-indicators, the speed of response to epidemics, the quality of the health care system, its compliance with international standards, and health risks from the environment. The indicator value for 2019 was applied in the study (Global Health Security Index, 2021) to reflect the readiness to fight the pandemic, the prerequisites for which were discovered at the end of 2019.

SUS is Coronavirus Susceptibility Index (Knoema, 2021b). This index is a comprehensive indicator reflecting the susceptibility to coronavirus and the potential risk of infection. It is calculated on the basis of indicators that reflect health care costs, the availability of medical personnel and hospital beds, the availability and quality of medical care (which partially correlates with the HEAL index); the Rule of Law Index (LAW indicator); as well as the development of information and communication technologies, urbanization, population density, the population aged 80 and over, as the population category most vulnerable to coronavirus, the development of trade, and the government efficiency. Based on the particular indicators with reference to which the index is calculated, it should be the most accurate indicator of the effectiveness of the fight against the pandemic. But this is not confirmed in practice, as evidenced by the data from China. For China, the Coronavirus Susceptibility Index is the highest among 155 countries in the ranking (Knoema, 2021b), while the mortality rate is one of the lowest in the world (3.322 deaths per million population, while the average world indicator is 298.6542 deaths per million population) (Hasell et al., 2020). Therefore, along with the SUS indicator, we separately considered the LAW, DEM, HEAL indicators, presumably affecting the effectiveness of the fight against the pandemic, the significance of which has been proven in the previous case studies ofthe countries of Eastern Europe (Vasiljeva et al., 2020).

$\mathrm{MOR}_{\mathrm{EXPECT}}$ is the expected mortality indicator, which is understood in this study as the excess of life expectancy over the average age of the population and which is calculated as a ratio of these variables. The values of the corresponding indicators as at the beginning of 2020 were employed (Hasell et al., 2020).

VAC is vaccination coverage - a percentage of the population vaccinated at the end of 2020 (Hasell et al., 2020).

The highest COVID-19 case fatality rate is among the population with cardiovascular diseases and diabetes (Abate, Checkol \& Mantefardo, 2021). Therefore, the Cardiovasc death rate (CARD) and diabetes prevalence (DIABET) values as at the beginning of 2020 were used as factors affecting the effectiveness of the fight against the pandemic (Hasell et al., 2020).

The following group of indicators characterizes the countries' cultural peculiarities: 
-POW.DIST - Power Distance is an indicator characterizing the level of the social hierarchical order manifestation;

-INDIV - Individualism is an indicator identifying the ratio of individualism and collectivism in society;

-MASC - Masculinity. This indicator determines the ratio of the femininity manifestation (which is understood as the predominant manifestation of care and orientation toward ensuring the quality of life) and masculinity (based on competition and orientation toward success) in society;

-UNCER - Uncertainty Avoidance is an indicator that designates the community's desire to keep everything in check;

-LONG - Long Term Orientation is an indicator denoting the attitude of society to its traditions and the possibilities of their adaptation to current conditions to achieve future development goals;

-INDUL - Indulgence determines the degree of the community's control over its desires and impulses, adjusting them to social norms.

The current assessments of the Hofstede Insights (Hofstede Insights, 2021) for the culture components in the countries of the world were applied as the data for the analysis of the countries' cultural features.

The $\mathrm{GDP}_{\mathrm{GR}}$ and $\mathrm{MOR}_{\text {Covid }}$ indicators were the dependent variables.

The proposed list of indicators allows assessing the factors that can potentially affect the scale of the pandemic concerning the countries of the world and the effectiveness of the fight against it based on the stated research hypotheses. The research sample was initially formed from 194 countries of the world (Vogelstein \& Bro, 2020; List of World Leaders 2021, 2021). But it was reduced to 67 because of the lack of data for the selected indicators and due to the deletion of countries in which the highest leadership in 2020 was represented by both women and men or in which newly elected leaders over the course of the year were of another gender. The sample for modeling was formed using data for the following countries: Albania, Argentina, Bangladesh, Belarus, Belgium, Bulgaria, Bolivia,
Bosnia and Herzegovina, Hungary, Vietnam, Ghana, Guatemala, Germany, Denmark, Dominican Republic, Zambia, Israel, India, Indonesia, Jordan, Iraq, Iran, Ireland, Iceland, Spain, Italy, Kazakhstan, China, Colombia, Costa Rica, Latvia, Luxembourg, Malaysia, Morocco, Mexico, Mozambique, Nigeria, the Netherlands, New Zealand, Norway, Panama, Paraguay, Poland, Portugal, the Russian Federation, Romania, Salvador, Saudi Arabia, North Macedonia, Senegal, Serbia, Slovenia, the USA, Thailand, Turkey, Ukraine, Uruguay, Philippines, Finland, Croatia, Chile, Switzerland, Sri Lanka, Ecuador, South Korea, South Africa, and Japan.

Due to the different dimensions of indicators, different units of measurement, the values of indicators, used in the models, were standardized by the formula (Anysz, Zbiciak \& Ibadov, 2016):

$$
X_{\text {norm }}=\frac{X_{i}-X_{i \min }}{X_{i \max }-X_{i \min }} \text {, }
$$

where $X_{\text {norm }}$ is the standardized value of the $i$-th indicator;

$X_{i}$ is the actual value of the $i$-th indicator;

$X_{i \text { min }}, X_{i \text { max }}$ are the minimum and maximum values of the $i$-th indicator, respectively, in the study sample.

The EViews 10 software product was applied to conduct the regression analysis. The study evaluated the impact of all independent variables (except GDP $(2020), \mathrm{GDP}_{(2019)}$, and $\mathrm{GDP}_{(2018)}$ ) on both dependent variables. The impact of $\mathrm{GDP}_{(2020)}$, $\mathrm{GDP}_{(2019)}$, and $\mathrm{GDP}_{(2018)}$ indicators on the effectiveness of the fight against the pandemic was assessed by the means of the influence on the $\mathrm{MOR}_{\text {Covid }}$ indicator. The $\mathrm{GDP}_{\mathrm{GR}}$ indicator was not used as a performance sub-indicator to avoid functional interdependencies between GDP and $\mathrm{GDP}_{\mathrm{GR}}$.

\section{RESULTS}

Descriptive statistics of the study sample demonstrate that female-headed countries are more effective in responding to the pandemic (Table 1). 
Table 1. Indicators of the effectiveness of the fight against the COVID-19 pandemic by country leaders' gender.

\begin{tabular}{|l|c|c|c|c|c|c|c|c|c|}
\hline \multirow{2}{*}{ Indicator } & \multicolumn{3}{|c|}{$\begin{array}{c}\text { GDP per capita growth } \\
\text { rate }\end{array}$} & \multicolumn{3}{c|}{$\begin{array}{c}\text { Mortality rate, people } \\
\text { per 1,000 population }\end{array}$} & \multicolumn{2}{c|}{$\begin{array}{c}\text { Mortality rate adjusted } \\
\text { for testing coverage }\end{array}$} \\
\cline { 2 - 9 } & $S 1^{1}$ & $S 2^{2}$ & $S 3^{3}$ & $S 1$ & $S 2$ & $S 3$ & $S 1$ & $S 2$ & $S 3$ \\
\hline $\begin{array}{l}\text { Average } \\
\text { value of the } \\
\text { indicator }\end{array}$ & 0.9534 & 0.9258 & 0.9407 & 0.3930 & 0.2892 & 0.3095 & 0.0031 & 0.0028 & 0.0023 \\
\hline $\begin{array}{l}\text { Empirical t- } \\
\text { test values } \\
\text { for samples } \\
1,2\end{array}$ & \multicolumn{3}{|c|}{$4.90^{*}$} \\
\hline $\begin{array}{l}\text { Empirical t- } \\
\text { test values } \\
\text { for samples } \\
2,3\end{array}$
\end{tabular}

${ }^{1}$ Sample 1 - female-headed countries;

${ }^{2}$ Sample 2 - male-headed countries;

${ }^{3}$ Sample 3 - both female- and male-headed countries;

* Statistically significant (at $\mathrm{p}=0.05$ ) differences between the mean values of pandemic control effectiveness indicators across samples.

The calculations show that the female-headed countries revealed the smallest economic recession due to the impact of the pandemic. This decline in 2020 amounted to $4.66 \%$ on average for the sample. The largest economic decline is in male-headed countries - $7.42 \%$. Differences in the values of these indicators checked by the ttest among samples 1 and 2, 2 and 3 are statistically significant at a significance level of $p$ $=0.05$. The empirical values of 4.90 for samples 1 and 2 of 3.22 for samples 2 and 3 are higher than the tabular value of 1.99. The empirical value of 1.78 for samples 1 and 3 is lower than the tabular value of 2.07, which indicates that the differences in the economic effectiveness of combating the pandemic for female-headed countries and countries where women and men hold the highest leadership positions are insignificant.

The mortality rate is highest for female-headed countries -0.3930 cases per 1,000 population, the lowest for male-headed countries -0.2892 cases per 1,000 population. Mortality rates adjusted for testing coverage are minimal when men and women collaborate in leadership positions. The highest mortality (both adjusted and not adjusted for testing coverage) is among female-headed countries. These differences in mortality rates between the groups of femaleheaded and male-headed countries are statistically significant by the t-test at a significance level of $\mathrm{p}=0.05$.

Statistical estimates indicate that femaleheaded countries are more cost-effective in combating the pandemic, and from the standpoint of minimizing the level of confusion, this group of countries is less effective than male-headed countries.

The revealed regularity may be the result of the influence of the factors other than gender. Therefore, in order to investigate the influence of gender factor and other indicators on the effectiveness of combating the pandemic, 
regression models were built. At the same time, the gender factor (the GENDLEAD variable) was used as one of the independent variables, and also as a grouping variable to check the Chow test for the presence of a different nature of the indicators' influence on the effectiveness of combating the pandemic, depending on the leadership gender. The features of regression models, describing the influence of factors on the effectiveness of the fight against the pandemic, are presented in Table 2.

Table 2. Features of regression models describing the impact of factors on the effectiveness of combating the COVID-19 pandemic.

\begin{tabular}{|c|c|c|c|}
\hline \multicolumn{4}{|c|}{ Dependent Variable: GDP $_{\mathrm{GR}}$} \\
\hline \multicolumn{4}{|c|}{ Method: Least Squares } \\
\hline \multicolumn{4}{|c|}{ Included observations: 67} \\
\hline Variable & Coefficient & t-Statistic & Prob. \\
\hline DEM & -0.6425 & -3.056083 & 0.0139 \\
\hline LAW & 0.3049 & 2.641541 & 0.0304 \\
\hline Intercept term & 0.7414 & 4.316647 & 0.0000 \\
\hline F-statistic & 62.4303 & $\begin{array}{l}\text { Heteroskedasticity Test: Prob (F- } \\
\text { statistic) }\end{array}$ & 0.8450 \\
\hline Prob (F-statistic) & 0.0000 & Normality Test: Prob & 0.6682 \\
\hline $\begin{array}{l}\text { Ramsey Test: Prob (F- } \\
\text { statistic) }\end{array}$ & 0.7403 & Chow Test: Prob (F-statistic) & 0.5695 \\
\hline \multicolumn{4}{|c|}{ Dependent Variable: $\mathrm{MOR}_{\mathrm{CovID}}$} \\
\hline \multicolumn{4}{|c|}{ Method: Least Squares } \\
\hline \multicolumn{4}{|c|}{ Included observations: 67} \\
\hline Variable & Coefficient & t-Statistic & Prob. \\
\hline GEND $_{\text {LEAD }}$ & -0.0259 & -3.553155 & 0.0010 \\
\hline DEM & 0.5122 & 3.044361 & 0.0028 \\
\hline HEAL & -0.4099 & -2.916432 & 0.0055 \\
\hline INDUL & 0.3268 & 2.135752 & 0.0298 \\
\hline LAW & -0.5233 & -3.008493 & 0.0041 \\
\hline UNCER & 0.1818 & 2.044716 & 0.0466 \\
\hline Intercept term & 0.1718 & 2.019735 & 0.0489 \\
\hline F-statistic & 26.4252 & $\begin{array}{l}\text { Heteroskedasticity Test: Prob (F- } \\
\text { statistic) }\end{array}$ & 0.4382 \\
\hline Prob (F-statistic) & 0.0001 & Normality Test: Prob & 0.5716 \\
\hline $\begin{array}{l}\text { Ramsey Test: Prob (F- } \\
\text { statistic) }\end{array}$ & 0.7199 & Chow Test: Prob (F-statistic) & 0.4057 \\
\hline
\end{tabular}

The models developed evidence for a significant impact on the effectiveness of combating the pandemic of such factors as the Rule of Law Index (LAW) and the DI (DEM) that affect both the resulting indicators: $\mathrm{GDP}_{\mathrm{GR}}$ and $\mathrm{MOR}_{\text {Covid. }}$ The LAW indicator is a stimulating factor in combating the pandemic: the higher is the indicator's value, the less significant is the economic downturn and the lower is the mortality rate. The DEM Index is a disincentive factor. The revealed nature of these indicators' impact is explained by the fact that higher LAW values and lower DEM values contribute to compliance with anti-epidemic rules and recommendations, which facilitates minimizing the number of infected people, the mortality rate and the lockdown time reduction in the country while exerting a positive effect on economic indicators.

Despite the statistically significant differences in $\mathrm{GDP}_{\mathrm{GR}}$ level between the countries presided over by women and the ones presided over by 
men as illustrated by Table. 1 , the gender factor does not have a significant effect on the $\mathrm{GDP}_{\mathrm{GR}}$ indicator (Table 2).

In addition to LAW and DEM, COVID-19 mortality rate is also significantly affected by gender $\left(G{ } D_{\text {LEAD }}\right)$, Global Health Security Index (HEAL), and cultural factors: Indulgence (INDUL) and Uncertainty Avoidance (UNCER). Contrary to previous studies [13,21], there is a regularity revealed that COVID-19 mortality rate adjusted for testing coverage is lower in countries presided over by men. It enables us to conclude that in combating against the pandemic, the decisiveness and uncompromising inherent to men is more important than the humanistic rhetoric more inherent to female leaders. The findings obtained confirm H1 Hypothesis in the part that the gender identity of world countries' leaders affects the behavior effectiveness in combating the COVID-19 pandemic from the viewpoint of minimizing the mortality rate. But they deny the Hypothesis that female country leaders act more effectively in countering COVID-19 spreading.

LAW and DEM indicators were found to be the only ones having a statistically significant impact on economic efficiency and members of the indicator group affecting the COVID-19mortality rate. Besides the indicators mentioned, the mortality rate is significantly influenced by the Global Health Security Index. Higher Global Health Security Index values evidence for a more developed medical system that facilitates conditions for preventive measures implementation and contributes to a more effective therapy resulting in a lower mortality rate. It confirms $\mathrm{H} 2$ Hypothesis.

High values of Indulgence and Uncertainty Avoidance indicator create obstacles in combating coronavirus in the countries provided for by H3 Hypothesis.

The impact of other independent variables on the effectiveness of combating the pandemic is statistically insignificant at 0.05 significance level. $\mathrm{H} 4$ and $\mathrm{H} 5$ Hypotheses are not confirmed based on the outcomes of the regression models drafted.

The adequacy of the constructed models (Table 2 ) is confirmed by:
1. The Sample sufficiency comprising 67 observations;

2. The Fisher's criterion (F-statistic); its empirical values by models (62.4303 for the model of assessing the effectiveness of combating the pandemic by GDP ${ }_{\mathrm{GR}}$ indicator and 26.4252 for the model of assessing the effectiveness of combating the pandemic by MOR $_{\text {covid }}$ indicator) exceed the table value of 3.15 at 0.05 significance level;

3. The Student's t-test (t-Statistic); its empirical values for independent variables exceed the table value of 2.0 for the model of assessing the effectiveness of combating the pandemic by $\mathrm{GDP}_{\mathrm{GR}}$ indicator and by $\mathrm{MOR}_{\text {Covid }}$ indicator. It confirms the statistical significance of the independent variables;

4. The correlation coefficients' values between the independent variables that are statistically insignificant and evidence for the absence of multicollinearity in the models;

5. The Ramsey Test -0.7403 and 0.7199 Prob indicator values for this test exceed the border value of 0.05 , which confirms the relevant choice of the regression model type;

6. The Heteroskedasticity Test -0.8450 and 0.4382 Prob indicator values for this test exceed 0.05 evidence for the absence of heteroscedasticity in models;

7. The Normality Test - its results evidence for the normal distribution of models' residuals as empirical values of the Prob index for this test (0.6682 and 0.5716) exceeding 0.05;

8. The Chow Test. This test was used to identify possible structural shifts in models by gender. According to this test, Prob $\geq 0.05$ evidencing for the absence of structural shifts and the identical nature of DEM, HEAL, INDUL, LAW, UNCER indicators' influence the effectiveness of combating the pandemic, regardless of leaders' gender.

The priority of factor impact on the effectiveness of combating the pandemic was assessed according to the average elasticity coefficients calculated using the developed regression models. The calculated elasticity coefficients show the percentage change in the normalized value of the resulting indicator $\left(\mathrm{GDP}_{\mathrm{GR}}, \mathrm{MOR}_{\mathrm{COVID}}\right)$ under the change by $1 \%$ of 
independent variables relative to their average normalized value for countries' sample.

\section{DISCUSSION}

The study findings suggest an empirical assessment related to political elites' behavior effectiveness in Vietnam and other countries during the pandemic as a factor of enhancing public confidence in the political regime and the successfulness of government's anti-crisis strategy. The research results revealed that in most countries of America, Europe, Asia, Australia, and Africa, the political elite behavior effectiveness in combating the spread of COVID19 pandemic was determined mostly based on the rule of law factors, the political regime, cultural features and political leader's gender within the period of implementing the anti-crisis strategy to overcome the economic consequences of the pandemic and minimize the population mortality rate. At the same time, it was found that the gender factor is not significant in neutralizing the economy development threats, while men as political leaders have a more significant impact on the population mortality rate.

The results obtained evidenced that with an increase in the normalized value of the DI by $1 \%$ relative to the average value for countries' sample, the per-capita GDP growth rate decreases by $0.63 \%$. With the increase in the normalized value of the Rule of Law Index by $1 \%$, the per-capita GDP growth rate increases by $0.23 \%$. It proves the DI priority compared to the Rule of Law Index in terms of their impact on economic development and the opposed nature of these indicators' impact. As to influencing the Covid mortality rate, gender is the highest priority. Changing the gender of country's political leaders (replacing women with men) results in the mortality rate decrease by $8.75 \%$. The DI is the next indicator by priority; the increase in its normalized value by $1 \%$ leads results in the mortality rate decrease by $0.90 \%$. The increase in the normalized of the Rule of Law Index by $1 \%$ leads to the mortality rate decrease by $0.72 \%$. The increase in the normalized value of the Global Health Security Index by $1 \%$ results in the mortality rate decrease by $0.59 \%$. The increase in the normalized value of the Indulgence Indicator by $1 \%$ results in the mortality rate growth by $0.44 \%$. The increase in normalized value of the Uncertainty Avoidance Indicator by $1 \%$ results in the mortality rate growth by $0.39 \%$.

It is worth mentioning that the political regime of people power in countries during the pandemic is a destructive factor, as well as the cultural features of a society that mitigate the effectiveness of combating against the pandemic when they are manifested. It can be explained by the fact that countries with higher Indulgence indicator values are characterized by population commitment to satisfying their desires, life enjoyment, optimism, and, as a consequence, underestimation of the pandemic threat, unwillingness to sacrifice their desires threatening their health and life. A high level of the Uncertainty Avoidance indicator evidences for the need to comply with established behavior rules and traditions that can adversely affect the compliance with anti-epidemic rules and creates uncertainty conditions. Consequently, in combating the pandemic, the presence of a collectivist culture is effective. In particular, it is inherent to Vietnam. And countries with a liberal culture and with a predominantly political regime of people power become a destructive factor in the effectiveness of combating the pandemic. The cultural factor (society beliefs and attitudes, historical traditions and wellestablished social practices) predetermines the severity of measures enforced for quarantine violations. Therefore, it can be claimed that the authoritarian behavior of political leaders in combating a pandemic seems to be a more efficient anti-crisis strategy.

According to the obtained research results, due to the fact that Vietnam is a country presided over by men, it has a lower MOR covid $_{\text {normalized }}$ value by $8.75 \%$ compared to countries presided over by women. Vietnam's DI makes 2.94 with a sample average of 6.11 ; it contributes to lower GDP decline rates per capita and lower mortality rates than the world average. Due to this indicator, the normalized $\mathrm{GDP}_{\mathrm{GR}}$ values in Vietnam are $49.65 \%$ higher, and the $\mathrm{MOR}_{\text {covid }}$ indicator is $77.77 \%$ lower than the average for the countries examined. Higher HEAL value (49.1 with a world average of 48.1) contributes to MOR $_{\text {covid }}$ normalized value decrease by $2.49 \%$. Cultural ways and habits also restrain virus 
spreading: INDUL and UNCER values for Vietnam make 35 and 30 , respectively, with a world average of 46.5 and 66.2. The contribution of these factors to the mortality rate decrease is estimated at $16.60 \%$ and $26.49 \%$. The disincentive factor in combating the pandemic is a low Law Index level (0.49) compared to the sample average (0.58). Lower values of this indicator contribute to the $\mathrm{GDP}_{\mathrm{GR}}$ normalized value decrease by $9.53 \%$ and $\mathrm{MOR}_{\text {covid }}$ normalized value increase by $32.14 \%$ compared to the average for the sample examined.

Despite the general global decline in GDP per capita, this indicator in Vietnam increased in 2020 (Knoema, 2021a). The mortality rate adjusted by testing coverage made 0.00002 with a world average of 0.003 (Hasell, 2020) that illustrates the effectiveness of combating the pandemic. The revealed nature and strength of factors' impact (assessed via elasticity indicators) on the effectiveness of combating the pandemic is also inherent to Vietnam. But for this country, the priority is set in more detail based not only on elasticity indicators, but also on indicators' deviations for Vietnam from the average values for the country sample examined. Compared to the average values of indicator affecting the effectiveness of combating the COVID-19 pandemic in the world, Vietnam shows the impact of pandemic combating factors, such as gender, level of people power, healthcare system development level, and Indulgence and Uncertainty Avoidance factors. The nature of impact exerted by these factors, and the percentage of normalized value deviations of the effectiveness of pandemic-combating indicators were calculated depending on factors' impact based on the regression models developed.

In contrast to the research data available in current scientific publications on this issue (Windsor et al., 2020Erman \& Medeiros, 2021), the study results obtained are based on the assessment of behavioral strategy effectiveness selected by the state political leaders during the humanitarian crisis using an integrated approach. This approach enables to analyze the priority of the system of factors providing the most efficient ways of social control and combating the COVID-19 pandemic spreading. Moreover, the effectiveness of enhancing public trust in political leaders' behavior is assessed not only in terms of reducing SARS-CoV-2 case fatality rate, but also in terms of consequences of country's economy development as an outcome of enforcing the anti-epidemiological measures.

\section{CONCLUSIONS}

It should be noted that within the framework of the article, the constituent items of each factor that promotes the political elite behavior effectiveness in combating the pandemic were not examined; thus, they require a more detailed study for each factor and conducting a sociological survey. But in the future, as our scientific priority, we shall focus on a detailed study of all effectiveness constituent factors in view of identifying the most exact destructive and complementary sub-factors that provide the highest level of public confidence in the political elite in combating the pandemic. Besides, the formula used in the article for calculating the ratio of COVID-19 death percentage in the total population to the testing level as one of subindicators for assessment of the pandemic combat effectiveness, is not a universal and generally accepted one. But this disadvantage is minimized through the fact that for all countries the calculation of this indicator is identical and reflects the essence of the problem researched.

\section{REFERENCES}

Abate, S.M., Checkol, Y.A., \& Mantefardo, B. (2021). Global prevalence and determinants of mortality among patients with COVID-19: A systematic review and meta-analysis. Ann. Med. Surg., 6, 102204, doi:10.1016/j.amsu.2021.102204.

Anysz, H., Zbiciak, A., \& Ibadov, N. (2016). The influence of input data standardization method on prediction accuracy of artificial neural networks. Procedia Eng., 153, 66-70.

Archer, K., \& Levey, I.R. (2021). Trust in Government Lacking on COVID-19's Frontlines. https://news.gallup.com/opinion/gallup/2 96594/trust-government-lackingfrontlines-covid.aspx.

Bosancianu, C.M., Dionne, K.Y., Hilbig, H., Humphreys, M., Sampada, K.C., Lieber, N., \& Scacco, A. (2021). Political and Social 
Correlates of COVID-19 Mortality. https://osf.io/preprints/socarxiv/ub3zd/.

Desson, Z., Lambertz, L., Peters, J.W., Falkenbach, M., \& Kauer, L. (2020). Europe's COVID-19 outliers: German, Austrian and Swiss policy responses during the early stages of the 2020 pandemic. Health Policy Technol., 9, 405-418.

Edelman Trust Barometer 2020. (2021). https://cdn2.hubspot.net/hubfs/440941/T rust\%20Barometer\%202020/2020\%20Edel man\%20Trust\%20Barometer\%20Global\%20 Report.pdf?utm_campaign=Global:\%20Tru st\%20Barometer\%202020andutm_source= Website.

Edelman Trust Barometer 2021. (2021). https://www.edelman.com/trust/2021trust-barometer\#top.

Erman, A., \& Medeiros, M. (2021). Exploring the Impact of Cultural Variability on COVID19-Related Mortality: A Meta-Analytic Approach. https://www.researchgate.net/publication /342573645_Exploring_the_impact_of_cul tural_variability_on_COVID-19related_mortality_A_metaanalytic_approach

Garikipati, S., \& Kambhampati, U. (2021). Women Leaders are Better at Fighting the Pandemic.

https://voxeu.org/article/women-leadersare-better-fighting-pandemic.

Global Health Security Index. (2021). Retrieved January 13, 2021, from:

https://www.ghsindex.org/wpcontent/uploads/2020/04/2019-GlobalHealth-Security-Index.pdf.

Grech, V., \& Grech, P. (2020). WITHDRAWN: COVID-19: Combined supply-side and demand-side shocks, so lift restrictions (carefully) lest GPD declines ultimately kill more than COVID-19. Early Hum. Dev., 105209, doi:10.1016/j.earlhumdev.2020.105209.

Hasell, J., Mathieu, E., Beltekian, D., Macdonald, B., Giattino, C., Ortiz-Ospina, E., Roser, M., \& Ritchie, H. (2020). A cross-country database of COVID-19 testing. Sci. Data, 7 , 345.

Herrera, H., Konradt, M., Ordoñez, G., \& Trebesch, C. (2021). The Political Consequences of the Covid Pandemic:
Lessons from Cross-Country Polling Data. https://voxeu.org/article/politicalconsequences-covid-pandemic.

Hofstede Insights. Country Comparison. Retrieved January 13, 2021, from: https://www.hofstedeinsights.com/country-comparison/.

Johnson, C., \& Williams, B. (2020). Gender and political leadership in a time of COVID. Politics and Gender, 16, 943-950.

Knoema. (2021a). Gross Domestic Product per Capita in Current Prices. Retrieved January 13, 2021, from: https://knoema.com/atlas/ranks/GDP-percapita.

Knoema. (2021b). Global Coronavirus Susceptibility Index by Knoema. Retrieved January 13, 2021, from: https://knoema.ru/xtkvoxc/globalcoronavirus-susceptibility-index-byknoema.

List of World Leaders 2021. (2021). https://197travelstamps.com/list-ofworld-leaders/.

Maiti, A., Zhang, Q., Sannigrahi, S., Pramanik, S., Chakraborti, S., Cerda, A., \& Pilla, F. (2021). Exploring spatiotemporal effects of the driving factors on COVID-19 incidences in the contiguous United States. Sustain. Cities Soc., 68, 102784, doi:10.1016/j.scs.2021.102784.

Megits, N. (2016). The Impact of Russia-China Trade Relationship on the U.S. Economy. Journal of Eastern European and Central Asian Research (JEECAR), 3(2), 12, doi: 10.15549/jeecar.v3i2.135

Nurunnabi, M. (2020). COVID-19 in Saudi Arabia: What we know so far. Journal of Southwest Jiaotong University, 55, doi:10.35741/issn.0258-2724.55.6.14.

Nurunnabi, M., Alhawal, H.M., \& Al Bassam, R.Y.A. (2020). National responses and economic strategies to address COVID-19 in Saudi Arabia. Journal of Southwest Jiaotong University, 55, doi:10.35741/issn.0258-2724.55.6.30.

Polidori, C.M., Sies, H., Ferrucci, L., \& Benzing, T. (2021). COVID-19 mortality as a fingerprint of biological age. Ageing Res. Rev., 67, 101308, doi:10.1016/j.arr.2021.101308. 
Qureshi, A.I., Suri, M.F.K., Chu, H., Suri, H.K., \& Suri, A.K. (2021). Early mandated social distancing is a strong predictor of reduction in peak daily new COVID-19 cases. Public Health, 190, 160-167.

Rangone, N. (2018). Making law effective: Behavioural insights into compliance. Eur. J. Risk Regul., 9, 483-501.

Sjöstedt, M., \& Linell, A. (2021). Cooperation and coercion: The quest for quasi-voluntary compliance in the governance of African commons. World Dev., 139, 105333.

Van Bavel, J.J., Baicker, K., Boggio, P.S., Capraro, V., Cichocka, A., Cikara M., Crockett, M.J., Crum, A.J., Douglas, K.M., Druckman, J.N., Drury, J., Dube, O., Ellemers, N., Finkel, E.J., Fowler, J.H., Gelfand, M., Han, S., Haslam, S.A., Jetten, J., Kitayama, S., Mobbs, D., Napper, L.E., Packer, D.J., Pennycook, G., Peters, E., Petty, R.E., Rand, D.G., Reicher, S.D., Schnall, S., Shariff, A., Skitka, L.J., Smith, S.S., Sunstein, C.R., Tabri, N., Tucker, J.A., van der Linden, S., van Lange, P., Weeden, K.A., Wohl, M.J.A., Zaki, J., Zion, S.R., \& Willer, R. (2020). Using social and behavioural science to support COVID-19 pandemic response. Nature Human Behavior, 4, 460-471.

Vasiljeva, M., Neskorodieva, I., Ponkratov, V., Kuznetsov, N., Ivlev, V., Ivleva, M., Maramygin, M., \& Zekiy, A. (2020). A predictive model for assessing the impact of the COVID-19 pandemic on the economies of some Eastern European countries. J. Open Innov. Technol. Mark. Complex., 6, 92, doi:10.3390/joitmc6030092.

Vogelstein, R.B., \& Bro, A. (2020). Women's Power Index. Council on Foreign Relations. https://www.cfr.org/article/womenspower-index.

Windsor, L.C., Reinhardt, G.Y., Windsor, A.J., Ostergard, R., Allen, S., Burns, C., Giger, J., \& Wood, R. (2020). Gender in the time of COVID-19: Evaluating national leadership and COVID-19 fatalities. PLoS One, 15 , e0244531.

World Health Organization. (2021). As More Go Hungry and Malnutrition Persists, Achieving Zero Hunger by 2030 in Doubt. UN Report Warns. https://www.who.int/news/item/13-072020-as-more-go-hungry-andmalnutrition-persists-achieving-zerohunger-by-2030-in-doubt-un-reportwarns.

World Justice Project. (2021). WJP Rule of Law Index 2020. Retrieved January 13, 2021, from: https://worldjusticeproject.org/ourwork/research-and-data/wjp-rule-lawindex-2020.

Yang, W.-Y., \& Tsai, C.-H. (2020). Values, collective security, and privacy: Taiwan people's response to COVID-19. Asian Journal for Public Opinion Research, 8 , 222-245.

\section{ABOUT THE AUTHOR}

Huong Thi Tran, email: tranhuongxdd@gmail.com

Huong Thi Tran is the Lecturer at the Academy of Journalism and Communication (AJC), HCMA, Vietnam. 